\title{
A imprensa brasileira e a síndrome da erva daninha
}

\author{
Wilson da Costa Bueno*
}

\section{Resumo}

A imprensa brasileira, apoiada numa perspectiva essencialmente econômica, tem contribuído para difundir um falso conceito de sustentabilidade, contaminado pelos interesses das grandes empresas multinacionais. Por isso, considera o conhecimento local, a defesa da biodiversidade e a resistência aos transgênicos como traços de uma cultura primitiva que se encontra em oposição ao pensamento científico. Para reverter esse processo e estabelecer uma postura crítica em relação à chamada "mentalidade química", é essencial capacitar os jornalistas, mostrando-lhes como esses interesses atuam fortemente na indústria da comunicação. Este artigo identifica as formas de atuação das empresas multinacionais, que visam ao monopólio das sementes e dos insumos agrícolas.

Palavras-chave: Jornalismo Ambiental - Jornalismo e Agribusiness - Jornalismo e Biodiversidade

A análise do comportamento da imprensa brasileira diante das questões ambientais emergentes (mudanças climáticas, transgênicos, agrotóxicos, biodiversidade e biopirataria etc) só pode ser realizada, satisfatoriamente, se pudermos dispor de dois cenários abrangentes: 0 perfil do jornalismo brasileiro contemporâneo e as formas de atuação/ intervenção de segmentos industriais que impactam o meio ambiente.

* Wilson da Costa Bueno é jornalista, professor do Programa de Pós-Graduação em Comunicação Social da UMESP e professor de Jornalismo da ECA/USP. Mestre e doutor em Comunicação Social e especialista em Jornalismo Científico e Comunicação Rural pela USP. Diretor da Comtexto Comunicação e Pesquisa.

Comun. Inf., v. 6, n. 2, p.13-30, jul./dez. 2003 
Mudanças drásticas têm ocorrido tanto no universo da mídia (e no jornalismo, em particular) como no conjunto de atores que, apoiados estritamente na racionalidade econômica, atentam contra a sustentabilidade, degradando o solo, o ar e a água, em nome do lucro e do progresso técnico.

Essas mudanças têm contribuído para que a comunicação e o debate dos temas ambientais sejam penalizados, de tal modo que, de maneira contundente, podemos admitir que, à exceção de alguns nichos na grande imprensa e das chamadas mídias ambientais, os meios de comunicação têm feito o jogo dos grandes interesses. A falta de uma postura crítica e a adesão, sem restrições, às benesses prometidas pelo modelo agroexportador brasileiro comprometem a qualidade da informação jornalística e, conseqüentemente, a democratização do conhecimento ambiental.

\section{A imprensa fragilizada}

A indústria da comunicação no Brasil, particularmente os grandes jornais, vem atravessando, nos últimos anos, uma crise sem precedentes. Menos pelas condições impostas pela realidade brasileira e mais pela adoção de processos de gestão obsoletos, as empresas jornalísticas têm acumulado dívidas crescentes, tornando-se frágeis e vulneráveis.

Evidentemente, a cena brasileira, sobretudo nos anos recentes, não tem dado trégua aos empresários, desestimulados ao investimento pelos juros exorbitantes, pela carga tributária excessiva e pela instabilidade permanente da economia nacional, reféns dos humores do mercado (especialmente o financeiro) externo. Esse componente estrutural está presente, portanto, na crise da indústria da comunicação, mas não a justifica plenamente porque outros setores, submetidos ao mesmo constrangimento, têm, inclusive, experimentado picos de crescimento.

Concebidos ou administrados como empresas familiares, os veículos jornalísticos têm tido dificuldade para implementar uma administração moderna, profissionalizada, na verdadeira acepção do termo. O esforço das famílias no sentido de manter a todo custo o controle dos veículos impede que outros parceiros deles se aproximem, para injetar, ao mesmo tempo, recursos que lhes garantam o crescimento e novas idéias que permitam superar o atual impasse.

Comun. Inf., v. 6, n. 2, p.13-30, jul./dez. 2003 
Esse, certamente, é um dos motivos que explicam o fato de que, mesmo com a abertura para a participação do capital estrangeiro na indústria da comunicação brasileira, os investidores externos continuem retraídos, como se descrentes da potencialidade do negócio da informação no Brasil. ${ }^{1}$

O desaparecimento de muitos títulos de jornais e revistas nos últimos anos, o processo acelerado de concentração e de fusões de empresas jornalísticas e a apropriação das mídias pelas igrejas apontam para um futuro nada promissor. Muitos veículos, individualmente ou em conjunto, estão batendo às portas do BNDES, buscando irrigar suas receitas à custa do Governo, num processo de capitulação que pode ser fatal para a independência de suas linhas editoriais.

É preciso agregar a esse fato um outro não menos preocupante: os veículos jornalísticos, pressionados pela "quebra do caixa", têm engendrado estratégias comerciais equivocadas, oferecendo aos anunciantes formas "criativas" de intervenção no produto editorial, confundindo (talvez seja melhor dizer iludindo) a audiência (leitores de jornais e revistas, radiouvintes, telespectadores e internautas). Os publieditoriais (anúncios disfarçados de matérias) e os projetos de mercado/marketing (de que resultam páginas, cadernos ou encartes que fazem a apologia de organizações empresariais ou de governos) infestam a mídia brasileira, ao mesmo tempo em que o colunismo explode, o que significa perda de espaço e de autonomia, e a abertura do flanco para a atuação de assessorias de imprensa/comunicação e de agências de publicidade das grandes corporações. Nunca o assédio dos anunciantes à imprensa foi tão descarado e, certamente, nunca encontrou terreno tão propício para fazer valer os seus interesses.

O que há pouco tempo fosse talvez regra para os veículos de menor porte, sem recursos e sem ética, passa a ser percebido, com insistência, nos grandes jornais e revistas, ou seja, uma aproximação perigosa entre informação e marketing, entre redação e setor comercial e a perda, pelos veículos, da capacidade de gerar as suas próprias pautas. Muitos jornalistas, na TV (vide o escândalo recente do merchandising no jornalismo esportivo) ou nas colunas de jornais e revistas (e, agora, as vilãs não são apenas as colunas sociais, tradicionalmente vistas como espaço para tráfico de influência e de corte aos poderosos), passam a assumir sua condição de empresários (donos de agências de comunicação), estabelecendo uma condição nebulosa para sua atuação na imprensa de massa. A informação na mídia brasi-

Comun. Inf., v. 6, n. 2, p.13-30, jul./dez. 2003 
leira, mais do em qualquer outra época, está à mercê de interesses excusos.

Há quem afirme, como o professor Manuel Chaparro, um dos mais lúcidos críticos da imprensa nacional, que os nossos jornais se tornaram reféns das fontes empresariais (ou do governo), perdendo, dessa forma, a capacidade de exercer a sua postura crítica. Provavelmente, essa capitulação aos interesses empresariais explique a drástica redução das redações (o enxugamento do mercado tem sido avassalador, particularmente nos últimos três anos) e o rejuvenescimento das equipes, quase sempre associado à deterioração dos salários pagos aos jornalistas. A crise da imprensa tem empurrado excelentes profissionais para as gerências/diretorias de comunicação das organizações empresariais ou os tem estimulado a abrir o seu próprio negócio, reforçando esse desequilíbrio entre o que se pauta autonomamente nas redações e o que se importa, se copia do mercado. A imprensa está, cada vez mais, envolvida no universo dos releases, das coletivas, das abordagens inteligentes das assessorias, do media training e das famigeradas "viagens a convite de". A independência editorial vem sendo vendida, a cada dia, nos balcões de anúncios, nos projetos de marketing, nas festas de lançamentos de novos produtos, ainda que se possa identificar, aqui e acolá, focos de resistência, normalmente comandados por velhos jornalistas que ainda não se acostumaram com a idéia de que "tudo é marketing".

O importante é que o foco das empresas jornalísticas (as exceções apenas confirmam a regra) tem deixado, gradativamente, de ser a qualificação da informação e a capacitação dos profissionais de imprensa para se localizar no aumento de receita a qualquer custo. Para isso, vale concentrar o esforço na venda de livros, $\mathrm{CDs}$, fascículos (quase sempre de qualidade discutível), em vez de priorizar a melhoria das condições de trabalho nas redações. A "alma" do jornalismo está sendo posta à venda, o que representa uma ameaça real à consolidação da democracia em nosso País.

Esse cenário compromete a cobertura jornalística de maneira geral e, como poderemos ver, a própria cobertura da temática ambiental (como as de saúde, agribusines e ciência e tecnologia, para só citar três áreas muito próximas), especialmente porque, nesse caso, os interesses são poderosos e a capacitação dos jornalistas nem sempre adequada para fazer frente ao enorme desafio da comunicação especializada.

Comun. Inf., v. 6, n. 2, p.13-30, jul./dez. 2003 


\title{
Conhecimento e poder
}

Muitas empresas de tecnologia têm evidenciado um notável crescimento neste início de século, apoiadas em processos sofisticados de planejamento estratégico, que incluem a aniquilação dos adversários, a parceria com concorrentes e a constituição de cartéis para dominar o mercado. Experimentam, também, um processo acelerado de fusões e aquisições e diversificam-se para abranger áreas aparentemente distintas, como a biotecnologia, a produção de medicamentos, a produção de sementes, a de agrotóxicos etc.

Com certeza, está em curso uma vigorosa concentração de capital e de propriedade, de que tem resultado o domínio, por parte de poucas empresas, de mercados bilionários. Podemos citar, ainda que rapidamente, alguns dos setores mais sujeitos a essa concentração e tornar evidente o fato de que eles estão umbilicalmente vinculados às crises ambientais que assolam o planeta.

Basta mencionar algumas estatísticas dispersas, citadas por Pat Roy Money, para se chegar a uma conclusão assustadora:

\begin{abstract}
"Há 20 anos, nenhuma das 7.000 empresas de sementes de maior peso no mundo tinha uma porção identificável do mercado comercial de sementes. Hoje, as 10 principais empresas de sementes dominam um terço do mercado mundial. Há 20 anos, as maiores empresas farmacêuticas tinham cerca de 5\% do comércio mundial de medicamentos receitados. Hoje, as 10 maiores controlam mais de $40 \%$ do mercado. Há 20 anos, 65 empresas de química agrícola competiam no mercado mundial. Hoje, 9 companhias detêm aproximadamente $90 \%$ das vendas de pesticidas. Há 20 anos, a RAFI (Fundação Internacional para o Progresso Rural) não monitorava o mercado mundial de remédios veterinários. No entanto, hoje, 10 empresas detêm mais de dois terços das vendas mundiais."2
\end{abstract}

Embora os dados dessa concentração não sejam conhecidos (ou pelo menos divulgados) no caso brasileiro, sabe-se que a situação ainda é pior, já que somos apenas um espaço nesse universo global de intervenção das chamadas organizações transnacionais. As empresas brasileiras de sementes, só para citar um caso, foram, pouco a pouco, sendo adquiridas por grandes grupos e, para algumas culturas, como milho e trigo, o monopólio das sementes é um fenômeno irreversível.

Comun. Inf., v. 6, n. 2, p.13-30, jul./dez. 2003 
Assistimos, também, neste momento, à tentativa da Monsanto de, a partir da liberação da produção e comercialização da soja transgênica, dominar o mercado, impondo-nos a semente e o agrotóxico que, supostamente, protege a planta em crescimento. A imprensa, infelizmente, tem fechado os olhos a essa brutal investida, preocupada em dar guarida a argumentos aparentemente científicos das vantagens das sementes transgênicas e, com raras exceções (deve-se louvar o esforço dos jornalistas ambientais, das ONGs e mesmo da ministra do Meio Ambiente, Marina Silva, pressionada por seus colegas de ministério, seduzidos pelo "canto da sereia" da biotecnologia), inclui outros elementos nesse debate.

$\mathrm{Na}$ verdade, é preciso avançar mais nessa análise, agregando a contrapartida dessa expansão empresarial. O avanço da soja pelo cerrado e pela floresta brasileira, a utilização intensiva da água para irrigação das monoculturas, o despejo impressionante de veneno no campo (inseticidas, pesticidas etc) para combater as pragas, cada vez mais resistentes, têm desencadeado um processo criminoso de erosão ambiental.

A cada ano, milhares de espécies vegetais e animais são extintas, a devastação das matas e florestas ocorre num ritmo alucinante, a água doce torna-se patrimônio de poucos e o seu consumo supera à capacidade de renovação. Com tudo isso, a biodiversidade se vê profundamente ameaçada, porque a destruição dos ecossistemas compromete o futuro dos seres vivos.

Para quem acredita que apenas as plantas e animais estão em perigo, é fundamental ter sempre em mente que estamos todos nós no mesmo barco e que dependemos da água limpa, dos alimentos não contaminados, de alternativas sintonizadas com a nossa cultura para sobrevivermos. A idéia, ainda propagada especialmente pela mídia, de que o meio ambiente é externo à vida humana (e que temos o direito de nos apropriarmos dele para satisfazer nossas vontades e ambições) não resiste a uma análise, mesmo que superficial.

Essa erosão ambiental integra um processo maior de erosão, do qual podemos, de imediato, citar a erosão cultural. Voltemos a Pat Mooney para recuperar alguns dados contundentes:

"A cada ano se extinguem $2 \%$ das línguas do planeta; Mais de $80 \%$ de todos os livros traduzidos são traduzidos para apenas quatro línguas européias... seis companhias

Comun. Inf., v. 6, n. 2, p.13-30, jul./dez. 2003 
multinacionais (todas do Norte) controlam $80 \%$ do mercado mundial de música gravada..." 3

Essa erosão é particularmente penosa para a sociedade porque compromete o futuro do planeta. Cada língua nativa que desaparece leva consigo um conhecimento vital, secular. Com isso, deixamos de tomar contato com o vasto e rico "saber popular", cristalizado em informações sobre plantas e seus usos, sobre espécies animais, sobre formas de interação com a natureza, sobre manejo, sobre a própria vida humana. Novamente, Pat Mooney dá o alerta:

\begin{abstract}
"Tragicamente, toda essa erosão ambiental chega num momento de erosão de conhecimento igualmente sem precedentes. Em 1990 calcula-se que havia no mundo 10.000 línguas, mas hoje sobrevivem apenas 6.700 . E apenas $50 \%$ das que subsistem são ensinadas às crianças. Isto quer dizer que numa geração a metade das línguas atuais estará efetivamente extinta. Alguns estudos afirmam que $90 \%$ das línguas faladas em 1999 serão "história" em 2099. A metade das línguas que existem hoje tem menos de 10.000 falantes (e a metade delas menos de 1.000 falantes). Já na atualidade, um terço das terras da América do Sul estão ocupadas por pessoas que não falam nenhuma língua indígena". ${ }^{4}$
\end{abstract}

Estamos, portanto, em nome do progresso, destruindo identidades, sem percebermos que essa diversidade cultural, assim como a biológica, é que nos garante o futuro. A cultura homogeneizada, assim como a uniformidade biológica, nos deixa vulneráveis, porque nos submete a soluções únicas, a interesses monopolistas e, sobretudo, retira a nossa capacidade de enxergar o outro como parceiro. A erosão cultural e ambiental parte do pressuposto de que há dominadores e dominados e de que os mais produtivos (o conceito de produtividade moderno privilegia apenas a vertente econômica) devem prevalecer.

Talvez, por isso, os empresários e os governos (cúmplices desse processo de erosão) não façam a conta certa no momento de analisar a apropriação do ambiente pelo setor produtivo, contemplando o futuro com miopia. Numa perspectiva moderna, que considere o saber ambiental e a economia baseada em princípios ecológicos, não seria

Comun. Inf., v. 6, n. 2, p.13-30, jul./dez. 2003 
fácil justificar a produção intensiva, a monocultura exportadora, sem levar em conta o uso indiscriminado de recursos naturais. Para quem está preocupado apenas com a receita ("exportar é o que importa", este é o lema das economias e governos irresponsáveis!), não faz mesmo sentido imaginar que um quilo de carne de frango, obtido a partir do consumo elevado de energia (solo, água, sol etc), possa exaurir, a médio prazo, os nossos recursos. Para os que manipulam números e se extasiam com a notícia de que estamos batendo recordes sucessivos na produção de grãos, pouco importa se estamos comprometendo o meio ambiente, devastando ecossistemas, erodindo a biodiversidade. As políticas públicas, que se respaldam nessa perspectiva economicista, estarão, certamente, voltadas para fora (daí o esforço para modernizar os portos, ampliar a malha viária, enfim fazer circular produtos que serão consumidos, quase sempre, pelas populações e animais das nações hegemônicas), deixando sem proteção as populações nativas (em especial, os indígenas), as florestas tropicais e a água dos nossos rios.

Com respeito à água, só para não deixarmos de mencionar o descalabro que se comete contra esse fundamental recurso para a vida, é preciso lembrar que a estamos consumindo irresponsavelmente, em grande parte para sustentar a indústria em expansão. Cerca de 400 mil litros de água são utilizados, em média, para se produzir um carro e talvez esse dado explique o fato de, pouco a pouco, as montadoras internacionais (com incentivos fiscais dos Governos, que, demagogicamente, contabilizam empregos gerados e não os prejuízos ao meio ambiente) estarem transportando as suas fábricas para os países subdesenvolvidos. A indústria de computadores, nos EUA, consome um volume brutal de água doce desionizada, algo estimado em 1.500 bilhão de litros, devolvendo ao ambiente mais de 300 bilhões de litros de água com resíduos A indústria da mineração e do petróleo (só "na província canadense de Alberta, mais de 204 bilhões de litros de água, grande parte proveniente de aqüíferos, são bombardeados para dentro de poços de petróleo todos os anos para aumentar a pressão no reservatório e aumentar a produção") $)^{5}$ e o crescimento do uso da irrigação em ritmo incontrolável contribuem para essa perda e desperdício (o sistema tradicional chega a desperdiçar $80 \%$ da água). Estima-se que, hoje, em todo o mundo, existam 230 milhões de hectares de terra submetidas à irrigação e cita-se o caso da China que, para subsidiar esse sistema, construiu mais de 2 milhões de poços nas últi-

Comun. Inf., v. 6, n. 2, p.13-30, jul./dez. 2003 
mas quatro décadas. Não se pode ignorar também o caráter predador de inúmeras empresas que exploram o mercado, em expansão vertiginosa, inclusive no Brasil, da água engarrafada e que tem contribuído para a privatização de um bem comum.

"Pior ainda, a procura inexorável por suprimentos de água seguros para alimentar os apetites insaciáveis das corporações de engarrafamento de água está produzindo efeitos prejudiciais. Em comunidades rurais ao longo de grande parte do planeta, a indústria tem comprado áreas cultivadas para explorar os poços, mudando-se assim que os poços são esvaziados. No Uruguai e em outras partes de América Latina, as corporações de água estrangeiras têm comprado vastas áreas de selva e até mesmo sistemas de água inteiros para conservar para o desenvolvimento futuro. Em alguns casos, essas empresas acabam escoando o sistema de água da área inteira, não apenas da água em suas terras."

Além do uso intensivo da água, que deveria ser reservada para o consumo humano, as grandes empresas, notadamente as que atuam na produção de substâncias químicas, papel e celulose, fertilizantes, e agrotóxicos em geral poluem as águas e o solo de maneira irreversível. A ação dos Governos se limita a impor multas - que quase sempre não são pagas (pelo menos é o que acontece no Brasil)-, a quem polui, em vez de aumentar a fiscalização, para evitar que os danos ocorram. Novamente, assim como na área da saúde, gasta-se para curar a doença , mas não se investe na prevenção.

A imprensa, quase sempre alheia a esse cenário, não assume uma postura crítica, mais abrangente, ao lidar com as questões ambientais e reduz a cobertura à denúncia de vazamentos de óleo ou à extinção de espécies animais, tratando-os como acidentes eventuais. Não consegue enxergar que, estruturalmente, em função da expansão acelerada do capital e da irresponsabilidade de empresários inescrupulosos e de governos por eles financiados, $\mathrm{o}$ assalto ao meio ambiente acontece todos os dias. Imagina, portanto, que é possível, com atitudes simplistas, evitar que esse processo de degradação do ambiente se aprofunde. Em se tratando do meio ambiente, quase sempre, ainda que seja mais traumático, é mais apropriado fazer uma cirurgia do que aplicar pomada no curativo. Com paliativos, os problemas não são resolvidos, mas apenas postergados.

Comun. Inf., v. 6, n. 2, p.13-30, jul./dez. 2003 


\section{A síndrome da erva daninha}

A imprensa brasileira tem feito, sem espírito crítico, a apologia do modelo economicista e agroexportador, que contempla a preservação da biodiversidade como um entrave ao desenvolvimento; e a adesão sem limites à biotecnologia, com a legitimação da pesquisa e da ciência, como a única saída para o crescimento. Invariavelmente, vê também o conhecimento popular como exótico e primitivo.

Na prática, ela não tem discutido a fundo as implicações da consolidação desse modelo e tem assumido, ingenuamente, um conceito "cosmético" de sustentabilidade. Seduzida pelo marketing verde e pelos releases de empresas que, supostamente, praticam a chamada gestão ambiental, a imprensa tem difundido equivocadamente esse conceito, legitimando ações nefastas contra o meio ambiente. De alguma forma, ela aproxima os conceitos de desenvolvimento sustentável ao de progresso tecnológico, sem perceber que ambos se respaldam na perspectiva da racionalidade econômica aplicada à natureza, vista sempre como fornecedora de insumo para o sistema de produção capitalista.

Como afirma Mauro Oliveira Pires, "a expansão do mercado é fundamental para assegurar as taxas de lucros às empresas, o que permite o investimento em tecnologia para ampliar e reproduzir o mercado. Na opulência do sistema de apropriação, é necessário produzir cada vez mais mesmo que haja desperdício de matéria prima e energia".

A imprensa está convicta de que sempre é possível compatibilizar o crescimento econômico acelerado com a preservação do meio ambiente e, com isso, contribui para desarmar os espíritos e as mentes para a visualização das ações predatórias das empresas. A racionalidade empresarial, apoiada em maior produtividade e eficiência, não poupa, necessariamente, como insinua a mídia, os recursos naturais; pelo contrário, promove a sua degradação em nome do progresso.

Neste sentido, o conceito tradicional de desenvolvimento sustentável como o tipo de desenvolvimento que "atende às necessidades do presente sem comprometer as possibilidades de as gerações futuras atenderem às suas próprias", está definitivamente comprometido.

É possível perceber, no momento, outras situações similares, como a que caracteriza a difusão do conceito de responsabilidade social, aliás estreitamente associada ao de desenvolvimento sustentável. A imprensa, novamente sem exercer o papel que dela se espera, tem

Comun. Inf., v. 6, n. 2, p.13-30, jul./dez. 2003 
abrigado e difundido informações que visam formar a imagem positiva de organizações que, em sua essência e na sua prática, atentam contra a ética, a transparência e a própria vida dos cidadãos. Ela aceita como ação socialmente responsável os repetidos recalls das montadoras de automóveis, sem questionar os motivos pelos quais eles acontecem cada vez em maior número; ela festeja as campanhas da indústria de cigarros e de bebidas que, de maneira cínica, convidam os jovens, respectivamente, para fumar e beber com moderação, e noticia novos medicamentos, sem questionamento, envolvendo-se, promiscuamente, nas estratégias de marketing da indústria farmacêutica.

A imprensa, que se pauta, como vimos, por fontes externas, reporta a expansão da soja pelo cerrado e pela floresta com entusiasmo e é incapaz de se dar conta de que esse avanço irresponsável sobre a biodiversidade brasileira tem efeitos dramáticos para a nossa fauna, para a nossa flora, para a nossa cultura, enfim, para a nossa sobrevivência. Ela comunga com a visão empresarial, racionalista, mesquinha, de que o aumento das exportações (que, para os empresários, significa incremento dos lucros) justifica qualquer ação, repetindo também o discurso hipócrita de ministros, comprometidos com essa perspectiva economicista, mesmo porque, invariavelmente, eles têm sido recrutados da elite empresarial.

As grandes chamadas da imprensa estão voltadas para os sucessivos recordes de produção de grãos, sem se dar conta de que eles têm sido obtidos com culturas de exportação e que, paradoxalmente, quanto mais se produz, mais o custo dos alimentos aumenta internamente. Raramente, os veículos de comunicação contrapõem o aumento da produção de soja, por exemplo, à redução da produção de alimentos que constituem o "prato diário" do brasileiro quando dispõem desses dados, os vislumbram como naturais, como acidentes de percurso, como um mal necessário do desenvolvimento.

A imprensa, que faz a apologia do agronegócio como responsável pelo saldo em nossa balança comercial, não consegue perceber quem são os maiores beneficiados por essa expansão agrícola e não se pergunta porque "o aumento do bolo" não tem como contrapartida a partilha dos pedaços para os diversos segmentos da sociedade. A imprensa não sabe fazer contas e, por isso, não consegue formular uma pergunta óbvia: se a produção de grãos mais que duplicou em uma década, como pode ter a fome aumentado no Brasil?

Comun. Inf., v. 6, n. 2, p.13-30, jul./dez. 2003 
Esse equívoco tem se repetido quando focaliza a questão dos transgênicos, porque, não raras vezes, a imprensa endossa o argumento dos produtores de biotecnologia de que os transgênicos aumentarão a produtividade agrícola (o que, definitivamente, não está comprovado!) e que, em consequência, a fome no mundo poderá ser mais eficazmente combatida. Esquece-se ela de que os países ricos, onde está a sede dessas empresas, têm paulatinamente aumentado os subsídios aos seus produtores (vide o caso dos Estados Unidos e da Comunidade Européia) e criado entraves aos países em desenvolvimento, jogando, portanto, na contramão desse argumento falacioso.

A imprensa brasileira, que tem tratado a reforma agrária em suas páginas policiais, não percebe, também, que a preservação da biodiversidade tem estreita relação com o acesso à terra, porque 0 modelo de ocupação e de exploração dos nossos recursos naturais, que privilegia a monocultura exportadora, é que tem provocado a degradação do meio ambiente. A agricultura intensiva, não a familiar, embora possa, a curto prazo, contribuir para as exportações (e, efetivamente,contribui) não democratiza os lucros: quando muito estimula o surgimento de novas cidades no meio do sertão (assim como faz a indústria da mineração no norte brasileiro), que, ao longo do tempo, se tornarão refúgios de pessoas sem esperança.

A imprensa assume como inevitável e, o que é pior, como positiva, a adesão à chamada "cultura química" e noticia, sem qualquer postura crítica, a concentração das empresas produtoras de agrotóxicos, sem se preocupar com o fato de que ao utilizarmos intensivamente pesticidas, inseticidas e outros venenos, estamos comprometendo a saúde da terra, da água e a nossa própria saúde. O número de casos de intoxicação por agrotóxicos no País é alarmante, mas, com raras exceções, a mídia prefere frequentar os escritórios refrigerados dos fabricantes que os corredores dos hospitais (como o da Unicamp, em Campinas), para confrontar a realidade do crescimento econômico com a da degradação social.

A imprensa, infelizmente, não consegue perceber os vínculos estreitos entre representantes da comunidade científica e a comunidade empresarial, acreditando que as fontes da ciência, em princípio, não têm compromissos além dos muros das universidades e das paredes dos laboratórios. Assume, portanto, a neutralidade científica que, assim como a jornalística, constituem-se num mito. Os patrocinadores dos projetos científicos e tecnológicos costumam impor restrições se-

Comun. Inf., v. 6, n. 2, p.13-30, jul./dez. 2003 
veras à circulação de informações e, de há muito, a ciência a serviço do capital perdeu a sua virgindade.

Por não ter consciência dessa realidade, que está diante dos nossos olhos, a imprensa (e os governantes), invocaram a neutralidade científica no debate sobre os transgênicos, como se os atores envolvidos (as empresas, os ministros, os cientistas) fossem absolutamente isentos. Se os jornalistas se dispusessem a investigar, veriam que muitos cientistas assinam colunas nos jornais, ao mesmo tempo que são diretores do Conselho de Informação em Biotecnologia, uma entidade (uma ONG, dá para acreditar?) que é financiada pelas grandes empresas da área

A imprensa esforçou-se, nesse episódio, a serviço das empresas, para vender a idéia de que os ambientalistas estavam ideologizando o debate, apoiada numa visão ingênua de ciência isenta, neutra, sem compromissos, como se estivéssemos num mundo ideal, onde a relação' entre produção do conhecimento e poder (econômico, político, cultural) não existisse.

Os meios de comunicação, pouco acostumados à cobertura das políticas públicas de Ciência e Tecnologia, não as questionam e, dessa forma, não conseguem descobrir como os reduzidos investimentos em C \& T, direcionados para a solução dos problemas da Amazônia (apenas $4 \%$ do total), podem perpetuar as desigualdades e ameaçar o estudo e a proteção da biodiversidade brasileira.

A mídia, outra vez ingenuamente, faz alarde da transversalidade (políticas públicas definidas a partir de várias instâncias ou ministérios), quando, evidentemente, há um desequilíbrio escandaloso no Governo. $\mathrm{O}$ orçamento do Ministério do Meio Ambiente representa apenas $0,1 \%$ do total e, para ser claro, com isso não garante, como tem apontado o Instituto Socioambiental, ao menos a manutenção e a fiscalização dos nossos recursos naturais. ${ }^{8}$

Incomoda, particularmente, na cobertura do meio ambiente, o que podemos chamar, parodiando Vandana Shiva, de "síndrome da erva daninha", uma visão que penaliza toda aquela biomassa, toda cobertura vegetal que não presta para uso industrial. Ela está associada ao desconhecimento e ao preconceito em relação ao saber tradicional.

"O primeiro plano da violência desencadeada contra os sistemas locais do saber é não considerá-los um saber. A invisibilidade é a primeira razão pela qual os sistemas locais

Comun. Inf., v. 6, n. 2, p.13-30, jul./dez. 2003 
entram em colapso, antes de serem testados e comprovados pelo confronto com o saber dominante do Ocidente. A própria distância elimina os sistemas locais da percepção. Quando o saber local aparece de fato no campo da visão globalizada, faz com que desapareça, negando-lhe o status de um saber sistemático e atribuindo-lhes os adjetivos de 'primitivo' e 'anticientífico'".?

A mídia se apóia numa perspectiva positivista da ciência, que não reconhece a relação entre saber, conhecimento e poder, e que, de maneira equivocada, reforça a superioridade cognitiva da ciência moderna. Ao ignorar (ou desprezar) o saber local, a imprensa, bem como as empresas, elimina o espaço para o surgimento de alternativas. Ela legitima a ação dos grandes interesses, que ao contemplarem a floresta (contemplar pode ser um verbo muito delicado para quem tem a volúpia da destruição) vêem apenas a madeira valiosa, o princípio ativo extraído das plantas e dos animais, que pode ser consolidado em medicamentos altamente lucrativos, mas não conseguem vislumbrar, porque não lhes interessa, a floresta como um sistema biológico completo, que estabelece um "continuum" ecológico com o seu entorno.

A imprensa, como os grandes interesses, vê a floresta apenas como fornecedora de matéria-prima. Isto significa dar valor para a floresta apenas quando ela é retirada do seu habitat e, portanto, fora do seu contexto, e se transforma em capital. Não estabelece o vínculo entre a biologia , a cultura e a sociedade e, portanto, relega a segundo plano a importância de se manter a floresta viva.

\begin{abstract}
"A silvicultura científica foi a falsa universalização de uma tradição local de exploração dos recursos florestais que nasceu dos interesses comerciais limitados que viam a floresta somente em termos de madeira com valor comercial. Primeiro, reduziu o valor da diversidade da vida das florestas ao valor de umas poucas espécies que têm valor comercial e depois reduziu o valor dessas espécies ao valor de seu produto morto - a madeira". ${ }^{10}$
\end{abstract}

A "sindrome da erva daninha"consiste, pois, em descartar tudo aquilo que não tem valor comercial, e a imprensa, ao cobrir a exploração dos recursos naturais sob a lente das grandes empresas, age dessa forma. A copa das árvores, os frutos silvestres, o dejeto dos animais, o cipó e a forragem que cobre o chão são, para os empresários e para

Comun. Inf., v. 6, n. 2, p.13-30, jul./dez. 2003 
a imprensa, que com eles está mancomunada, erva daninha. Sob essa perspectiva, justifica-se a derrubada da floresta para a expansão da soja, o uso intensivo de agrotóxicos, as grandes reservas de eucaliptos, os recordes sucessivos de produção de um número reduzido de tipos de grãos. Na mão dos empresários e dos executivos financeiros, a floresta é apenas mais uma commodity.

Como corolário dessa síndrome, a semente deixa também de ser vista como produto e meio de produção, como explica Laymert Garcia dos Santos ("isto é, grão que será comido e que servirá como semente no próximo plantio"'11), e se transforma em mera matéria-prima. Nessa transformação, ela deixa de ser propriedade do agricultor e da população nativa.

\begin{abstract}
"A metamorfose tem, evidentemente,várias implicações. Em primeiro lugar, a semente auto-regeneradora se torna semente estéril que não se reproduz, quando por definição é um recurso gerador - através da intervenção tecnológica, a biodiversidade é transformada de recurso renovável em nãorenovável; além disso, a semente agora não produz por si mesma: necessita outros insumos (adubos químicos etc) que também serão industriais, isto é, uma nova interferência externa no ciclo ecológico da reprodução da semente. Em segundo lugar, a biotecnologia toma o todo pela parte e a parte pelo todo, pois trata a semente auto-regeneradora como mero germoplasma 'primário', e promove a semente estéril e carente a 'produto acabado'. Finalmente, ao transformar um processo ecológico de reprodução em processo tecnológico de reprodução, a biotecnologia retira a semente das mãos do camponês e do habitante da floresta, colocando-a na mão das corporações." 12
\end{abstract}

Mediante o domínio das patentes, as grandes corporações controlam o mercado de sementes, substituindo as sementes naturais pelas sementes engenheiradas. Destrói, com isso, a economia local e empurra os camponeses e as populações ribeirinhas para a zona de exclusão alimentar. Elas promovem, também, a homogeneização da dieta alimentar, consolidando novos hábitos, com o apoio maciço da mídia.

"A intensa propaganda comercial nos meios de comunicação de masa dos produtos dessas agroindústrias multinacionais de alimentos, aliado ao estímulo direto e subliminar para o

Comun. Inf., v. 6, n. $\dot{2}$, p.13-30, jul./dez. 2003 
consumo de massa, tem permitido a mudança dos hábitos alimentares de grande parte da população para a adoção de dieta alimentar similar àquela praticada pela classe média assalariada dos grandes centro urbanos: consumir alimentos originários das agroindústrias."13

O homem do campo, o indígena, o habitante da floresta passam a adquirir o produto industrializado, quando a natureza lhes oferecia um substituto natural, tornando-se dependentes e empobrecendo à custa das corporações de alimentos.

Essa situação precisa ser urgentemente revertida e a imprensa (e os jornalistas) têm um papel importante a desempenhar nessa autêntica cruzada de conscientização e de mobilização ambiental. Felizmente, esse movimento libertador já teve início, com as mídias ambientais brasileiras, as ONGs, os educadores ambientais e os profissionais (advogados, biólogos, ecologistas, agrônomos, médicos, nutricionistas etc). Esta é uma luta de todos porque preservar a biodiversidade, a água limpa e a identidade cultural dos povos subdesenvolvidos tem a ver com a nossa própria sobrevivência.

\section{Abstract}

The Brazilian Press, based on a economical perspective, has contributed in spreading a false concept of sustentability, infected by big multinational interests. It judges the local knowledge, the defense of biodiversity and the resistence in transgenics as traces of a primitive culture, in opposition of the scientific thought. To revert this process and to establish a critical posture concerning the "chemical mentality", it is essential to qualify the journalists, pointing out to them how the big interests actually work. This article identifies the ways of operation of multinational companies that intend to reach the monopoly of seed and agricultural outputs.

Key words: Environmental Journalism - Journalism and Agribusiness Journalism and Biodiversity.

\section{Notas}

1. O motivo principal, a meu ver, é que o investidor, no caso específico da indústria da comunicação, não quer apenas entrar com o dinheiro, mas influir no conteúdo, ou seja, mandar no negócio, e o empresário brasileiro ainda não se dispôs a fazer essa concessão integral. Como há uma tendência, mantida a incompetência gerencial da mídia, de que a crise se aprofunde, essa possibili-

Comun. Inf., v. 6, n. 2, p.13-30, jul./dez. 2003 
dade (de que o veículo ganhe ao mesmo tempo um investidor e um novo dono) acabará se tornando realidade.

2. Pat Roy Mooney. O século 21. Erosão, Transformação tecnológica e concentração do poder empresarial. São Paulo, Expressão Popular, 2002, p. 132.

3. Idem, Ibidem, p. 28 e 40.

4. Idem, Ibidem, p. 35.

5. Ver a respeito o trabalho de Maude Barlow e Tony Clarke, O Ouro Azul: como as grandes corporações estão se apoderando da água doce do nosso planeta, p. 17 e subseqüentes.

6. Idem, Ibidem, p. 173-4.

7. A perspectiva do desenvolvimento sustentável. In: Paul E. Little (Org.). Políticas ambientais no Brasil, p. 376.

8. Balanço Socioambiental do Governo Lula de janeiro a julho de 2003. Análise presente no site do Instituto (www.socioambiental.org/website/especiais/novogov2/index.shtm). Acessado em 18/08/2003. 23.

9. Vandana Shiva. Monoculturas da mente. São Paulo, Editora Gaia, 2003, p.

10. Idem, Ibidem, p. 32.

11. Laymert Garcia dos Santos. Politizar as tecnologias. São Paulo, Editora 34, p. 27

12. Idem, Ibidem, p. 28.

13. Horário Martins de Carvalho (Org.). Sementes: patrimônio do povo a serviço da humanidade (subsídios ao debate). São Paulo, Expressão popular, 2003,p. 96.

\section{Referências}

ABRANTES, J. S. Bio (sócio)diversidade e empreendedorismo ambiental na Amazônia. Rio de Janeiro: Garamond, 2002.

ARAGÃO, F. J. C. Organismos transgênicos: explicando e discutindo a tecnologia. São Paulo: Manole, 2003.

BARBIERI, J. C. Desenvolvimento e meio ambiente. $4^{\text {a }}$ ed. Petrópolis: Vozes, 1997.

BARLOW, M.; CLARKE, T. Ouro azul. São Paulo: M. Books do Brasil, 2003.

BENSUSAN, N. (Org.). Seria melhor mandar ladrilhar? Brasília: UnB, 2002.

BOADA, M.; TOLEDO, V. M. El planeta, nuestro cuerpo. México: Fondo de Cultura Económica, 2003.

BUENO, W. C. Jornalismo Científico, lobby e poder. In: DUARTE, J.; TEIXEIRA DE BARROS, A. Comunicação para a ciência, ciência para a comunicação. Brasília: Embrapa, 2003, p. 115-59.

CAMARGO, A. et al. Meio Ambiente Brasil: avanços e obstáculos pós-Rio 92. São Paulo: Estação Liberdade, 2002.

DIEGUES, A. C. (Org.). Etnoconservação: novos rumos para a proteção da natureza nos trópicos. $2^{\mathrm{a}}$ ed. São Paulo: Annablume, 2000.

Comun. Inf., v. 6, n. 2, p.13-30, jul./dez. 2003 
DUARTE, L. C. B. Política externa e meio ambiente. Rio de Janeiro: Zahar, 2003. FOLADONI, G. Limites do desenvolvimento sustentável. Campinas: Unicamp, 2002.

GARCIA DOS SANTOS, L. Politizar as tecnologias. São Paulo: Editora 34, 2003.

LEF, E. Saber ambiental. Petrópolis: Vozes, 2001.

LIMA, A.; BENSUSAN, N. (Org.). Quem cala consente? subsídios para a proteção dos conhecimentos tradicionais. São Paulo: Instituto Socioambiental, 2003.

LITTLE, P. E. (Org.). Políticas ambientais no Brasil. São Paulo: Petrópolis, 2003.

MARTINS DE CARVALHO, H. (Org.). Sementes: patrimônio do povo a serviço da humanidade (subsídios ao debate). São Paulo: Expressão Popular, 2003.

MOONEY, P. R. O século 21: erosão, transformação tecnológica e concentração do poder empresarial. São Paulo: Expressão Popular, 2003.

NOVAES, W. A década do impasse. São Paulo: Estação Liberdade, 2002.

REIGOTA, M. Ecologia, elites e intelligentsia na América Latina: um estudo de suas representaçõs sociais. São Paulo: Annablume, 1999.

SHIVA, V. Biopirataria. Petrópolis: Vozes, 2001.

SHIVA, V. Monoculturas da mente. São Paulo: Gaia, 2003.

SORRENTINO, M. (Org.). Ambientalismo e participação na contemporaneidade. São Paulo: Educ/FAPESP, 2002.

TRIGUEIRO, A. (Org.). Meio ambiente no século 21. Rio de Janeiro: Sextante, 2003.

URBAN, T. Missão (quase) impossível. São Paulo: Petrópolis, 2001.

VELLOSO, J. P. R.; CAVALCANTI DEALBUQUERQUE, R. (Coord.). Amazônia, vazio de soluções? Rio de Janeiro: José Olympio, 2002.

VERNIER, J. O meio ambiente. $5^{\text {a }}$ ed. Campinas: Papirus, 1994.

VILLIERS, M. Água. Rio de Janeiro: Ediouro, 2002.

Comun. Inf., v. 6, n. 2, p.13-30, jul./dez. 2003 